\title{
Transformation of Combustion Nanocatalysts inside Solid Rocket Motor under Various Pressures
}

\author{
Jun-Qiang Li ${ }^{1,+}{ }^{+}$Linlin Liu ${ }^{2,+}$, Xiaolong Fu ${ }^{1}$, Deyun Tang ${ }^{2}$, Yin Wang ${ }^{2}$, Songqi $\mathrm{Hu}^{2}$ and \\ Qi-Long Yan ${ }^{2, *(D)}$ \\ 1 Xi'an Modern Chemistry Research Institute, Xi'an 710065, China; 1lijq@sohu.com (J.-Q.L.); \\ fuxiaolong204@163.com (X.F.) \\ 2 Science and Technology on Combustion, Internal Flow and Thermo-structure Laboratory, Northwestern \\ Polytechnical University, Xi'an 710072, China; 1ll@nwpu.edu.cn (L.L.); tangdy@mail.nwpu.edu.cn (D.T.); \\ wongyin@mail.nwpu.edu.cn (Y.W.); pinecore@nwpu.edu.cn (S.H.) \\ * Correspondence: qilongyan@nwpu.edu.cn \\ + These authors contribute equally to this work.
}

Received: 31 January 2019; Accepted: 1 March 2019; Published: 6 March 2019

\begin{abstract}
In this paper, the dependences of the morphology, particle sizes, and compositions of the condensed combustion products (CCP) of modified double-base propellants (1,3,5-trimethylenetrinitramine (RDX) as oxidizer) on the chamber pressure $(<35 \mathrm{MPa})$ and nickel inclusion have been evaluated under a practical rocket motor operation. It has been shown that higher pressure results in smaller average particle sizes of the CCPs. The CCPs of Ni-containing propellants have more diverse morphologies, including spherical particles, large layered structures, and small flakes coated on large particles depending on the pressure. The specific surface area (SSA) of CCPs is in the range of 2.49 to $3.24 \mathrm{~m}^{2} \mathrm{~g}^{-1}$ for propellants without nickel are less dependent on the pressure, whereas it is 1.22 to $3.81 \mathrm{Ni}$-based propellants. The $\mathrm{C}, \mathrm{N}, \mathrm{O}, \mathrm{Al}, \mathrm{Cu}, \mathrm{Pb}$, and $\mathrm{Si}$ are the major elements presented on the surfaces of the CCP particles of both propellants. The compositions of CCPs from Ni-propellant are much more diverse than another one, but only three or four major phases have been found for both propellants under any pressure. The metallic copper is presented in CCPs for both propellants when the chamber pressure is low. The lead salt as the catalyst has been transformed in to $\mathrm{Pb}(\mathrm{OH}) \mathrm{Cl}$ as the most common products of lead-based catalysts with pressure lower than $15 \mathrm{MPa}$. When pressure is higher than $5 \mathrm{MPa}$, the nickel-based CCPs has been found to contain one of the following crystalline phases: $\mathrm{Pb}_{2} \mathrm{Ni}\left(\mathrm{NO}_{2}\right)_{6},\left(\mathrm{NH}_{4}\right)_{2} \mathrm{Ni}\left(\mathrm{SO}_{4}\right)_{2} \cdot 6 \mathrm{H}_{2} \mathrm{O}$, $\mathrm{C}_{2} \mathrm{H}_{2} \mathrm{NiO}_{4} \cdot 2 \mathrm{H}_{2} \mathrm{O}$, and $\mathrm{NiO}$, depending on the pressure.
\end{abstract}

Keywords: solid propellants; condensed products; catalytic combustion; compositions; rocket motor

\section{Introduction}

In spite of great advancements in the field of new energetic materials (EMs), the 1,3,5trimethylenetrinitramine (RDX) and ammonium perchlorate (AP) are still the most widely used ingredients as oxidizers in solid propellants [1]. In order to improve the combustion efficiency of solid propellants, one of the most effective ways is to add nano-sized catalysts. It has been shown that the catalysts could largely increase the burn rate and combustion efficiency of the solid propellants by changing the solid-state and gas-phase reaction mechanisms of between the oxidizers and fuels generated by the main ingredients such as binders, RDX, and AP. The effects of catalysts on the decomposition kinetics, reaction mechanisms, and burning rates, combustion characteristics have been widely investigated in the past decades. It has been shown that in case of nitramine-based propellants, the reaction of $\mathrm{CH}_{2} \mathrm{O}+\mathrm{NO}_{2} \rightarrow \mathrm{CO}+\mathrm{NO}+\mathrm{H}_{2} \mathrm{O}$ is proposed to be the most important one in their 
foam layer that determines the burn rate, where the evaporation and condensation of nitramines and nitric esters as the binder are responsible for the dominant mass transfer [2]. In the presence of extra oxidizer, such as potassium chlorate, the major gaseous decomposition products of RDX could be changed to $\mathrm{CO}, \mathrm{CO}_{2}, \mathrm{HCN}, \mathrm{NO}_{2}$, and $\mathrm{H}_{2} \mathrm{O}$ due to instant consumption of $\mathrm{CH}_{2} \mathrm{O}$ through the gas-phase transformation $\mathrm{CH}_{2} \mathrm{O}+\mathrm{O}_{2} \rightarrow \mathrm{HCO}+\mathrm{HO}_{2}$, resulting in higher reaction rate [3].

As one of the important groups of solid propellants, nitramine-containing modified double-base propellants are featured with low-emission (sometime smokeless), high mechanical strength, long shelf-life, and very low-pressure exponents. They are widely used in rocket motors of tactical missiles, with the higher burning rates (e.g., over $25 \mathrm{~mm} \mathrm{~s}^{-1}$ at $\left.7 \mathrm{MPa}\right)$ and low-pressure exponents $(\mathrm{n}<0.2)$ [4]. In order to improve the energy content of this type of propellants, usually maximum $5 \mathrm{wt} \%$ metal fuels (e.g., Al, Mg, B, and Ni) would be included [5]. The pressure exponent could be further decreased with extended pressure range by use of novel multi-functional catalysts [6]. The experiment phenomenon on combustion performance improvement has been widely reported by use of metal powder and novel catalysts as additives. However, the inherent mechanisms of these changes are still not so clear, even after much effort has been made on combustion mechanisms and the kinetic modeling of these processes [7]. In particular, some models have been developed to predict the comprehensive properties of the coarse condensed combustion products (CCPs) as a function of propellant formulation, burning conditions, agglomeration regularities, and geometric configuration of computational region $[8,9]$. Recent models on AP/HTPB propellants shows that under the condition of initial combustion pressure of $3.5 \mathrm{MPa}$ and a pressure reduction rate of $1000 \mathrm{MPa} / \mathrm{s}$, a narrow diffusion chemical reaction zone could be formed in the initial stage of depressurization. Further, the diffusion and premixed dual flame appears when the pressure drops to about 1.7 MPa [10]. For the same AP/HTPB system, three different reaction mechanisms have been proposed and simulated, which are based on the global chemistry using symbolic species for the three flames, a 12-species mechanism, and a 72-step reaction mechanism with 39-species, respectively [11]. Except for the numerical simulations, the chemical structure of the propellant flame could be predicted by ReaxFF reactive force field molecular dynamics and equilibrium thermodynamics simulations [12]. It has been found that the ReaxFF agrees considerably better with experimental results for minor species than the thermodynamic simulations.

It is widely accepted that the major combustion gaseous products from nitro-based propellants are $\mathrm{H}_{2} \mathrm{O}, \mathrm{CO}, \mathrm{CO}_{2}, \mathrm{H}_{2}$, and $\mathrm{N}_{2}$, whereas the $\mathrm{HCN}, \mathrm{NH}_{3}, \mathrm{CH}_{4}$, nitrogen oxides, benzene, acrylonitrile, toluene, furan, aromatic amines, benzopyrene, and various polycyclic aromatic hydrocarbons are detected in minor concentrations. However, the dark zone of the propellants has much different chemicals as the intermediates with higher molecular weight than those of the luminous flame zone [13]. The gas phase reactions could become more complicated if new energetic ingredients are included. For instance, in the case of metal hydrides, the $\mathrm{ZrH}_{2}$ was found to tune the decomposition behaviors of AP by enhancing the generation of $\mathrm{NO}$ in the high-temperature decomposition stage. The hydrogen released from $\mathrm{ZrH}_{2}$ may promote the combustion reactions in gaseous phases and therefore induce the two-stage combustion behaviors of the corresponding propellants [14]. Furthermore, the catalysts play the key role in both condensed and gas phase reactions but with much more uncertainty; even the solid-state catalytic decomposition behavior could be well characterized. The commonly used and evaluated catalysts include nano metric metal oxides [15] and ferrocene derivatives [16]. It has been proposed that both iron oxide and copper chromite are primarily acting on the condensed phase, whereas the ferrocene first acts simply as a highly reactive fuel. The resulted ferric oxide from ferrocene in the condensed phase would further catalyze the gas phase reactions [17].

In order for a complete description of the combustion mechanisms, the CCPs have to be clarified with more details. It is much more difficult to detect the intermediates of CCP in the combustion processes of solid propellants, especially under the high temperature/pressure rocket motor operation conditions due to very limited diagnosis techniques. However, the CCPs could be finally analyzed after quenching. The CCPs usually refer to the solid products of aluminized [18] or boron-containing [19] propellants, which are usually in micron sizes after agglomeration, if using the nanosized Al [20]. 
It has been found that a particle-laden flame zone with a sensibly reduced particle size is disclosed in the case of nanometer Al. To better understand the metal particles burning process, the reactions of a suspension of solid particles in a rapidly-heated oxidizing gas have been investigated. It has been shown that there are two reaction-onset mechanisms, which leads to a nontrivial dependence of the total reaction time on the particle size and solid-fuel concentration within the suspension [21]. Except for the experimental setups, various new diagnosis techniques have been developed to monitor the combustion process of the solid propellants. For instance, the time-resolved synchrotron $X$-ray imaging to view the in-situ formed aluminum agglomerates at corresponding rocket chamber pressures [22]. This technique provides real time critical data for understanding the combustion behavior of aluminized solid propellants in real rocket motors. Secondly, the gas phase species of the propellants could be experimental determined by time-of-flight mass spectrometry (ToFMS) to verify theoretical results from the density functional theory (DFT) calculations [23].

Even so much abovementioned achievement has been made in term of diagnosis and modeling of the solid propellant combustion, there is still a huge challenge to clarify the detailed reaction processes in the flame zone. It is essential to evaluate the combustion mechanisms under the operation conditions of a real rocket motor, based on which the interior ballistic characteristics could be well predicted. Owing to the extremely large specific surface areas, nano-sized catalysts have significant catalytic effects in both condensed and gas phases during decomposition and subsequent combustion, via activation of the reactants and acceleration of their transition state formations. In order to determine the relationship between the compositions, the chemical structure of the CCPs of modified double-base (MDB) propellants with different additives under a wide range rocket motor flow conditions are investigated, using a recently assembled facility with the capacity to capture almost all of the CCPs. The results may also give some evidence on how the pressure change the chemical structure of the CCPs, which can help setup the experiments for the target structure from flame synthesis under high pressure.

\section{Experimental Procedure}

\subsection{Preparation of the Propellant Samples and Nomenclature}

The MDB propellant samples were prepared by a cast-curing technique at a temperature of $70{ }^{\circ} \mathrm{C}$ for three days. The detailed ingredients of the slurry for the first typical formulation are as follows: Nitrocellulose (24.0 wt \%), Nitroglycerine (30 wt \%), RDX (35.5 wt \%), $\mathrm{Al}_{2} \mathrm{O}_{3}(2.0 \mathrm{wt} \%)$, Nickel (5.0 wt \%), and Lead/Copper salicylates (3.5 wt\%) as the catalysts. This sample is named as "LZ" in the following sections, where the ending number means the average maximum pressure in the rocket motor. For the second typical formulation are as follows: Nitrocellulose (24.0 wt \%), Nitroglycerine (30.0 wt \%), RDX $(40.5 \mathrm{wt} \%), \mathrm{Al}_{2} \mathrm{O}_{3}(2.0 \mathrm{wt} \%)$, and Lead/Copper salicylates (3.5 $\left.\mathrm{wt} \%\right)$. This sample is named as "JZ" in the following sections, where the ending number means the average maximum pressure in the rocket motor. The burn rate law for LZ and JZ propellants are $u=8.36 P^{0.422}(P=1.0-10.0 \mathrm{MPa})$ and $u=17.67 P^{0.201}(P=10-22 \mathrm{MPa})$, respectively.

\subsection{Rocket Motor Assembling and Combustion Condensed Products Collection}

Considering that the flame temperature of the MDB propellants is between $2500-3500 \mathrm{~K}$, but the ingredients of the condensed products must be analyzed at ambient conditions (about $293 \mathrm{~K}$ ), the CCPs have to be cooled down before all structure determinations. First, the reactions between the gaseous products with the condensed products need to be prevented during the cooling process. A facility has been designed in our lab to collect the CCPs and a schematic setup is shown in Figure 1 [24].

Air was first discharged from the collection tank using a vacuum pump and then the tank was filled with argon several times (no less than three times) to prevent reactions between the combustion products and oxygen from air. The propellant grain loaded in the solid rocket motor was ignited and the combustion products were ejected into the collection tank through a nozzle. After the combustion products were cooled down naturally and the CCPs were settled, which usually takes $2 \mathrm{~h}$, the door 
of collection tank can be opened for the sampling process. The combustion chamber pressure can be changed by adjusting nozzle throat diameter and the chamber pressure was measured by the pressure transducer during ignition and combustion processes. The CCPs were dried at $80{ }^{\circ} \mathrm{C}$ under vacuum for $12 \mathrm{~h}$ before analysis.

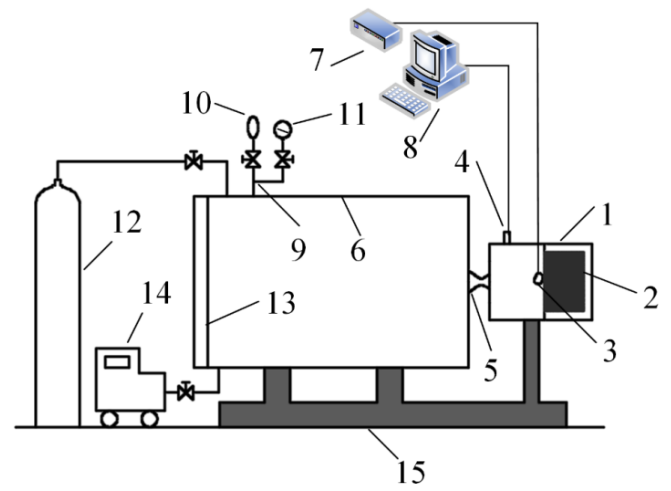

Figure 1. Schematic of the experimental facility: (1) solid rocket motor; (2) propellant grain; (3) igniter pad; (4) pressure transducer; (5) Laval nozzle; (6) collection tank; (7) ignition controller; (8) signal acquisition system; (9) gaseous product collecting piping/gas exhaust piping; (10) Teflon bag; (11) vacuum manometer; (12) hyperbaric argon cylinder; (13) door of collection tank; (14) vacuum pump; (15) steel holder and stabilizer; the shape of propellant grain, solid cylindrical coated with silicone rubber based heat insulation layer.

The combustion conditions of the propellants in this facility were almost the same as those in the solid rocket motor and the CCPs were widely dispersed in the stainless-steel collection tank with a large volume (about $2 \mathrm{~m}^{3}$ ), decreasing the probability of chemical reactions among the condensed-phase products to a certain extent. Large wall heat transfer occurs after ejection due to the high thermal conductivity of stainless-steel, which is also beneficial with respect to cooling the products. In addition, the collection tank was filled with inert gas (argon) and this also played an important role in avoiding reactions among the combustion products by increasing the cooling rate and diluting the combustion reactants.

It should be noted that some gaseous products ejected from the solid rocket motor, such as $\mathrm{H}_{2} \mathrm{O}$ may exist in the form of liquid or solid due to physical and chemical interactions during the cooling of the combustion products. The results of chemical analysis are reliable and can represent the real compositions of CCPs. Chamber pressure is important with respect to the compositions of the combustion products of the propellants. The experimental conditions, chamber pressures, and combustion time for the experiments of LZ and JZ formulations are shown in Table 1. In addition, the curves of chamber pressure vs. function time of two different MDB propellants are plotted in Figure 2.

Table 1. Experimental conditions and experimental results of LZ propellant grains.

\begin{tabular}{ccccc}
\hline Samples & $\boldsymbol{D}_{\mathbf{t}} / \mathbf{m m}$ & $\boldsymbol{P}_{\mathbf{c}, \mathbf{m a x}} / \mathbf{M P a}$ & $\boldsymbol{P}_{\mathbf{c}, \mathbf{a v}} / \mathbf{M P a}$ & $\boldsymbol{t}_{\mathrm{b}} / \mathbf{s}$ \\
\hline JZ-7 & 5.60 & 7.7 & 5.8 & 1.58 \\
JZ-12 & 4.70 & 12.5 & 9.4 & 1.27 \\
JZ-15 & 4.25 & 15.5 & 11.1 & 1.22 \\
JZ-20 & 3.91 & 19.8 & 13.6 & 1.14 \\
JZ-25 & 2.84 & 23.6 & 20.3 & 0.93 \\
LZ-0 & 7.50 & 0.8 & 0.5 & 2.96 \\
LZ-2 & 6.20 & 2.2 & 2.0 & 1.46 \\
LZ-5 & 5.40 & 6.6 & 5.3 & 1.63 \\
LZ-7 & 5.01 & 7.4 & 6.1 & 1.76 \\
LZ-9 & 4.50 & 9.5 & 7.8 & 1.74 \\
LZ-12 & 4.00 & 12.0 & 9.8 & 1.71 \\
LZ-18 & 3.30 & 17.7 & 13.2 & 1.56 \\
LZ-35 & 2.50 & 36.8 & 19.3 & 1.05 \\
\hline
\end{tabular}

Notes: $D_{\mathrm{t}}$ is nozzle throat diameter. $P_{\mathrm{c}, \max }$ is maximum chamber pressure of rocket motor. $P_{\mathrm{c}, \text { av }}$ is average chamber pressure of rocket motor. $t_{\mathrm{b}}$ is function time. 
Figure 2 shows that the chamber pressure cannot maintain constant during combustion of the propellants, which is common in the case of small rocket motors with very short working times, and a proper grain selection can help in getting neutral burning only in the case of full-scale rocket motors [25]. In order to investigate the effect of pressure on the combustion products, the time-averaged pressure $P_{c, a v}$ was used to characterize operation one. The pressure curve of the rocket motor could usually be divided into three parts, i.e., start-up phase, steady-state phase, and tail-off phase.
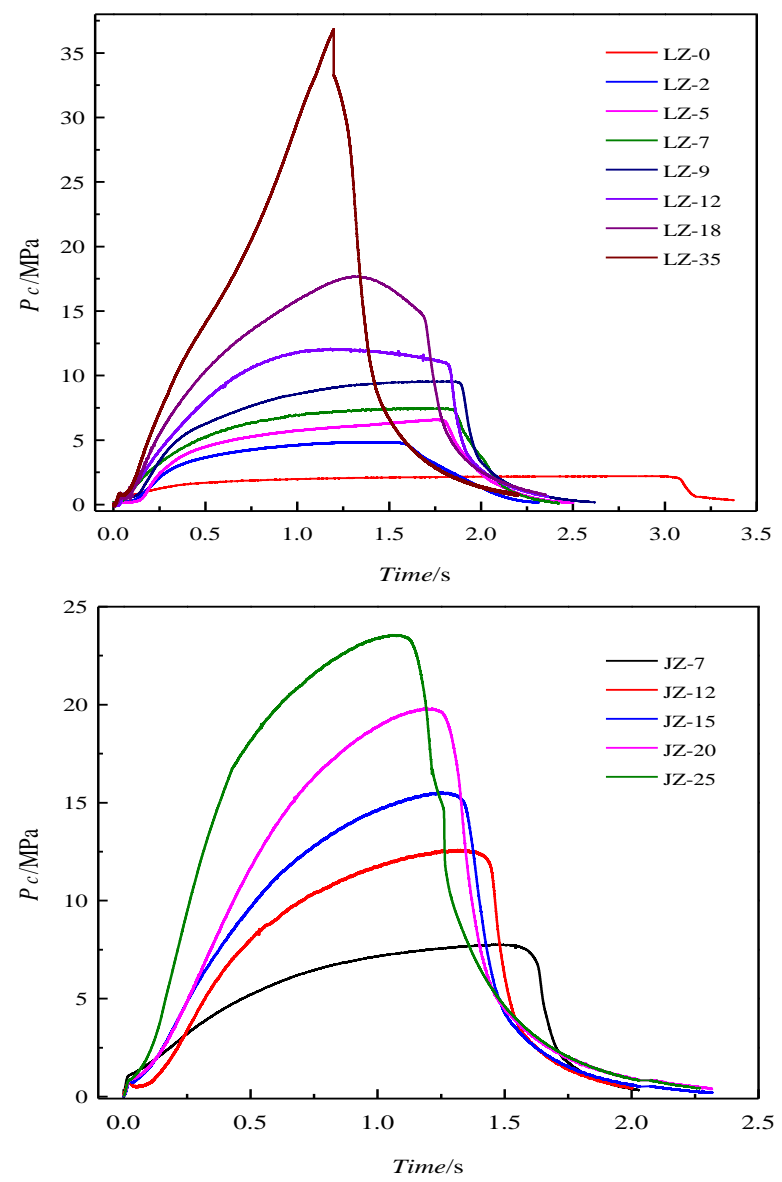

Figure 2. The pressure-time curves in the experimental rocket chamber for all firing measurements.

The steady-state phase clearly dominates the overall performance of the motor and the chamber pressure is usually calculated from this phase. Therefore, the starting point and end point of this phase must be determined. Figure 3 shows how to determine the function time of a solid rocket motor.

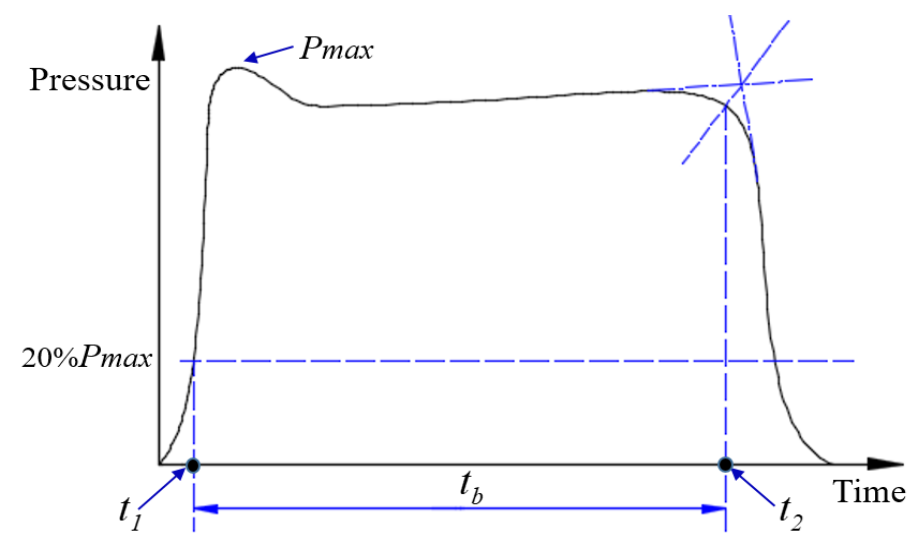

Figure 3. Function time diagram of solid rocket motor. 
In these experiments, the starting point of the steady-state phase, $t_{1}$, is defined as the time corresponding to the point of $20 \%$ of the maximum pressure on P-t curves; $t_{2}$, corresponds to the transition point of the steady state to pressure drop. The time-averaged chamber pressure $P_{\mathrm{c}, \text { av }}$ could be defined as follows:

$$
P_{\mathrm{c}, \mathrm{av}}=\frac{\int_{t_{1}}^{t_{2}} P d t}{t_{2}-t_{1}}
$$

It is clear that with the increase of the chamber pressure, the function time becomes shorter due to increased burn rate. The curves become less flat, especially for the one that has peak pressure of $35 \mathrm{MPa}$, which is unexpectedly out of the calibrated scale (25 MPa) of the pressure sensor.

\section{Results and Discussion}

\subsection{The Surface Morphologies of the Overall CCPS}

As the first step, the obtained CCPs are divided into three parts based on the particle sizes. The residues with centimeter sizes were picked out by naked eyes (Figure S1), which belongs to the exfoliated or fragmented linear layer of the propellant charges due to pressure fluctuation and ablation. The particles in micron sizes are collected by sedimentation in ethanol, whereas the upper suspended part containing nano-sized particles are subject to the Transmission Electronic Microscopy (TEM) analyses in a later section. The morphologies of the micron-sized CCPs are investigated by the Scanning Electronic Microscopy (SEM) technique, which are shown in Figures 4 and 5.

As shown in Figure $4 a-c$, there are a large amount of spherical particles with diameters of $1-3 \mu \mathrm{m}$ for JZ propellant, which does not contain Ni metal particles in comparison to LZ propellant. It is clear with the pressure increase, the average particle size decreases and also one could notice that once the pressure achieves $35 \mathrm{MPa}$, which is out of the range of the calibrated pressure sensor. The particles morphology seems return to be similar as the one obtained at lower pressure. It should be noted that the pressure of $35 \mathrm{MPa}$ is the peak pressure that has very short duration as shown in Figure 2. In this case, the pressure attenuation is dramatically after the peak value, so that the CCPs formed are similar to those obtained under lower pressure. It is shown in Figure $4 a_{1}-c_{1}$ that there are a large amount of amorphous nano-particles deposited on those large spherical particles. The elemental analyses show that these materials in most cases are nanocrystalline inorganic residues including carbon soot particles.
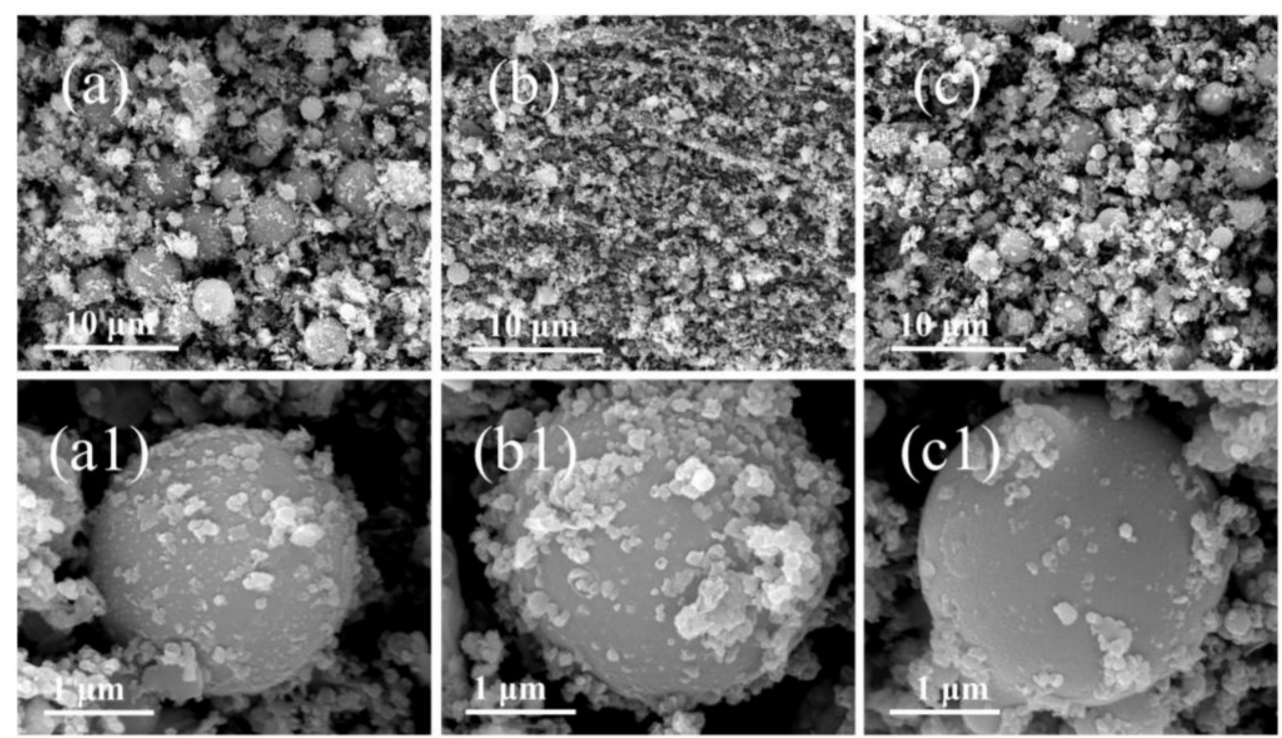

Figure 4. The SEM images of combustion products of JZ propellant grains: $\left(\mathbf{a}_{,} \mathbf{a}_{\mathbf{1}}\right) \mathrm{JZ}-15 ;\left(\mathbf{b}, \mathbf{b}_{\mathbf{1}}\right) \mathrm{JZ}-20$; and $\left(\mathbf{c}, \mathbf{c}_{\mathbf{1}}\right) \mathrm{JZ}-35$. 
Similarly, Figure 5 presents the surface structures of CCPs from LZ propellant at three different pressures as a comparison. With metallic Ni included, the LZ propellant has very different CCPs with a variety of morphologies, and the most typical ones are spherical particles, large layered structures, and small flakes coated on large particles. In general, the particle size of the spherical CCPs from LZ propellant is larger than those of JZ propellant. In order to clarify what elements are included in the CCPs, the EDS analyses have been done, with the spectra plotted in Figures S1 and S2, whereas the detailed elemental analyses are shown in Table S1, and the average atomic contents are summarized in Table 2.
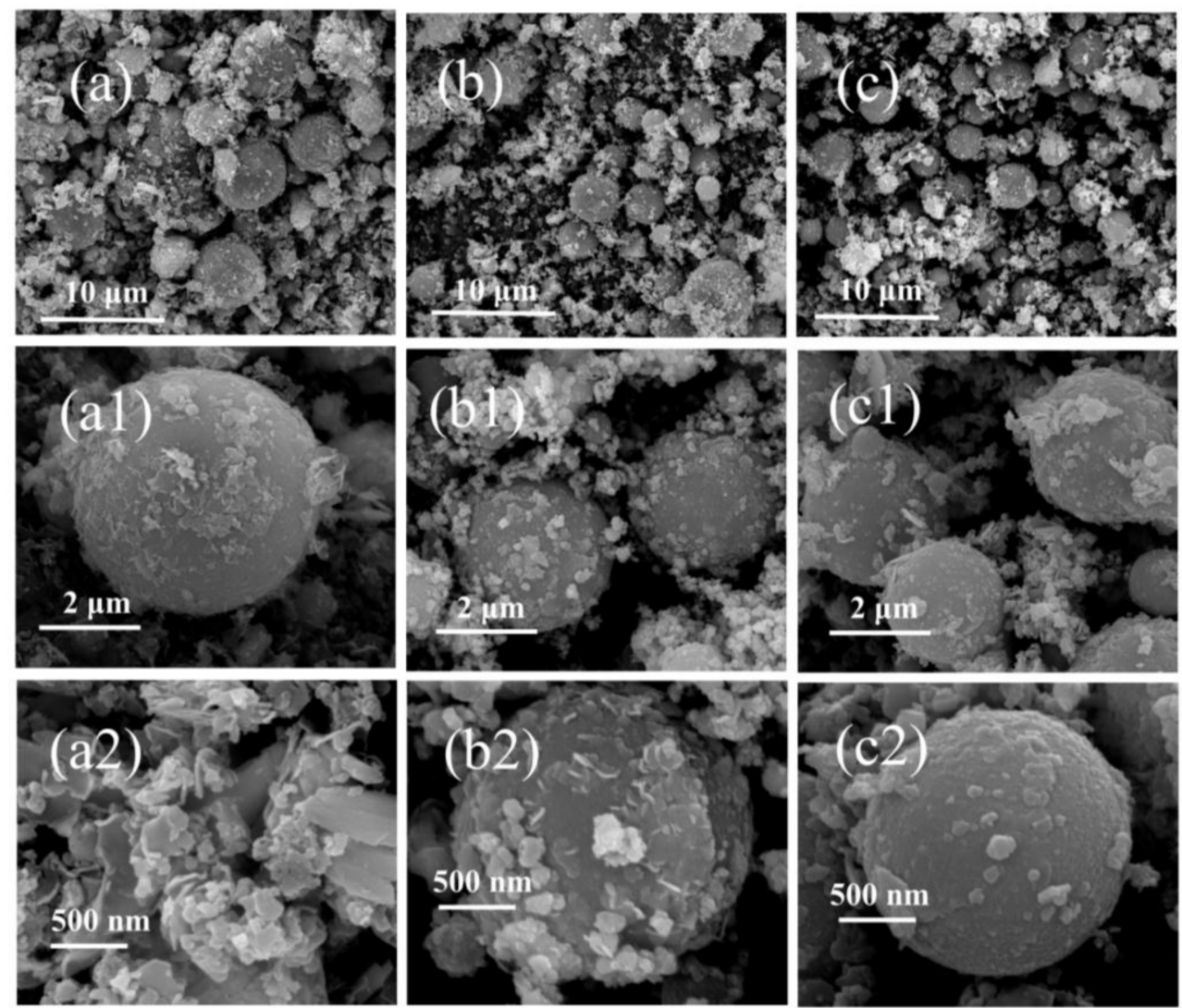

Figure 5. The SEM images of CCPs from LZ propellant $\left(\mathbf{a}, \mathbf{a}_{1}, \mathbf{a}_{\mathbf{2}}\right)$ LZ-7; (b, $\left.\mathbf{b}_{\mathbf{1}}, \mathbf{b}_{\mathbf{2}}\right)$ LZ-18; $\left(\mathbf{c}, \mathbf{c}_{\mathbf{1}}, \mathbf{c}_{\mathbf{2}}\right)$ LZ-35.

Table 2. Element distribution results of JZ and LZ propellant grains combustion products.

\begin{tabular}{ccccccc}
\hline \multirow{2}{*}{ Elements } & \multicolumn{7}{c}{ Average Atomic Contents (\%) } \\
\cline { 2 - 7 } & JZ-15 & JZ-20 & JZ-25 & LZ-7 & LZ-18 & LZ-35 \\
\hline $\mathrm{C} \mathrm{K}$ & 30.27 & 31.09 & 44.43 & 40.13 & 42.33 & 26.08 \\
$\mathrm{~N} \mathrm{~K}$ & 3.38 & 2.66 & 3.74 & 13.80 & 1.51 & 2.33 \\
$\mathrm{O} \mathrm{K}$ & 43.74 & 41.84 & 34.92 & 31.27 & 34.60 & 44.02 \\
$\mathrm{Al} \mathrm{K}$ & 9.55 & 10.18 & 7.60 & 4.16 & 7.50 & 11.80 \\
$\mathrm{Si} \mathrm{K}$ & 3.21 & 3.06 & 2.31 & 1.51 & 3.52 & 3.41 \\
$\mathrm{P} \mathrm{K}$ & 0.25 & 0.34 & 0.30 & 0.18 & 0.79 & 0.12 \\
$\mathrm{~S} \mathrm{~K}$ & 1.10 & 1.26 & 0.91 & - & - & - \\
$\mathrm{Cl} \mathrm{K}$ & 0.70 & 1.02 & 0.86 & 1.27 & 0.89 & 1.18 \\
$\mathrm{~K} \mathrm{~K}$ & 0.68 & 0.62 & 0.8 & 0.99 & 0.60 & 0.70 \\
$\mathrm{Ca} \mathrm{K}$ & 0.24 & 0.22 & 0.19 & 0.14 & - & 0.26 \\
$\mathrm{Fe} \mathrm{K}$ & 0.99 & 0.93 & 0.42 & 0.66 & 0.86 & 0.53 \\
$\mathrm{Ni} \mathrm{K}$ & 0.28 & 0.22 & 0.29 & 2.16 & 2.51 & 3.80 \\
$\mathrm{Cu} \mathrm{K}$ & 4.33 & 5.00 & 1.96 & 1.41 & 1.74 & 2.52 \\
$\mathrm{~Pb} \mathrm{M}$ & 1.33 & 1.60 & 1.31 & 2.36 & 2.27 & 3.28 \\
\hline
\end{tabular}


It is clear from Table 2 that, the $\mathrm{C}, \mathrm{N}, \mathrm{O}, \mathrm{Al}, \mathrm{Cu}, \mathrm{Pb}$, and $\mathrm{Si}$ are the major elements presented on the surfaces the CCP particles. For JZ propellants, with the increase of pressure, the content of carbon increases, and the $\mathrm{O}$ and $\mathrm{Si}$ decreases. The silicon element comes from the insulating material, which is based on a silicon rubber, indicating erosive burning to the insulation layer. However, higher pressure seems less erosive to the insulation layer for the JZ propellant free of metal fuel like nickel. It is opposite when the $5 \%$ of nickel is included as the metal fuel and flame stabilizer, where the erosive burning increases with the pressure, resulting in much higher $\mathrm{Si}$ content in the CCPs, e.g., it is $3.52 \%$ for LZ-18 and 3.06\% for JZ-20, respectively. The organic copper and lead salts are mainly transformed into CCPs. However, when the pressure is very high for the JZ propellant, there is no interaction between catalysts with the metal fuel. The content of $\mathrm{Cu}$ would drop to very low as $1.96 \%$, which is opposite of the LZ propellant. As shown in a later section, based phase analyses by X-ray Diffraction (XRD) show the higher pressure results in higher content of $\mathrm{Cu}$ and $\mathrm{Pb}$ in the CCPs, due to formation of some less volatile products such as minerals or alloys under the effect of nickel. The other minor elements such as $\mathrm{Ca}, \mathrm{K}$, and $\mathrm{Cl}$ are mainly from the complicated insulating materials. In terms of $\mathrm{Al}$ element, which comes from $\mathrm{Al}_{2} \mathrm{O}_{3}$ as a ballistic stabilizer, the content first increases and then decreases with the pressure for JZ propellant, whereas it largely increases with the pressure to even $11.8 \%$ when the peak pressure is $35 \mathrm{MPa}$ for $\mathrm{LZ}$ propellant. The interaction between the $\mathrm{Al}_{2} \mathrm{O}_{3}$ with metallic nickel is significant and the higher pressure is favorable for such mutual reactions, resulting in more nonvolatile products, which is responsible for such an increase in $\mathrm{Al}$ element content.

\subsection{The Particle Size Distributions of the Micron-sized CCPs}

Based on the separation of the nano-sized and micron-sized CCP particles by sedimentation method in aqueous media, the micron-sized particles are subject to a size distribution analysis. The corresponding distribution curves are plotted in Figures S3 and S4, with the detailed parameters for these plots are summarized in Table S2. In order for better comparison of the average values of the distribution based on repeated experiments, the normalized curves are shown in Figures 6 and 7 for JZ and LZ propellants, respectively. It is clear from Figure 6 that the micron-sized CCPs from combustion of JZ propellants can be divided into three groups in terms of particle sizes: submicron ones, media ones $(1-10 \mu \mathrm{m})$ and larger ones $(>10 \mu \mathrm{m})$. Most of the particles have the diameters less than $80 \mu \mathrm{m}$ for the JZ propellant burning at any pressure.

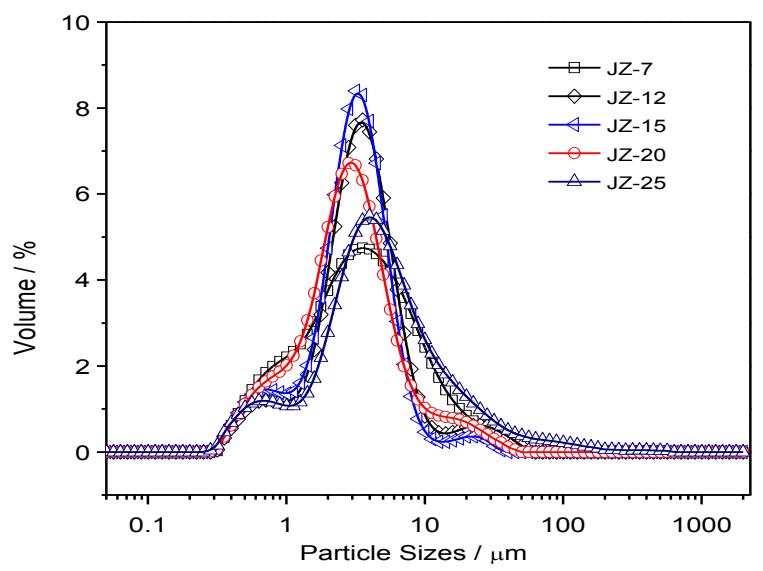

Figure 6. The particle size distributions of CCPs from combustion of JZ propellant grains under various pressures.

When the pressure is less than $12 \mathrm{MPa}$, the CCPs with submicron sizes are not well separated with the media sizes, as well as the larger sizes. It means that the size boundary is not so clear under lower pressure burning of JZ propellant. In comparison, when the pressure is higher than $15 \mathrm{MPa}$, the three peaks for three groups of particle sizes become more independent with more obvious boundaries. 

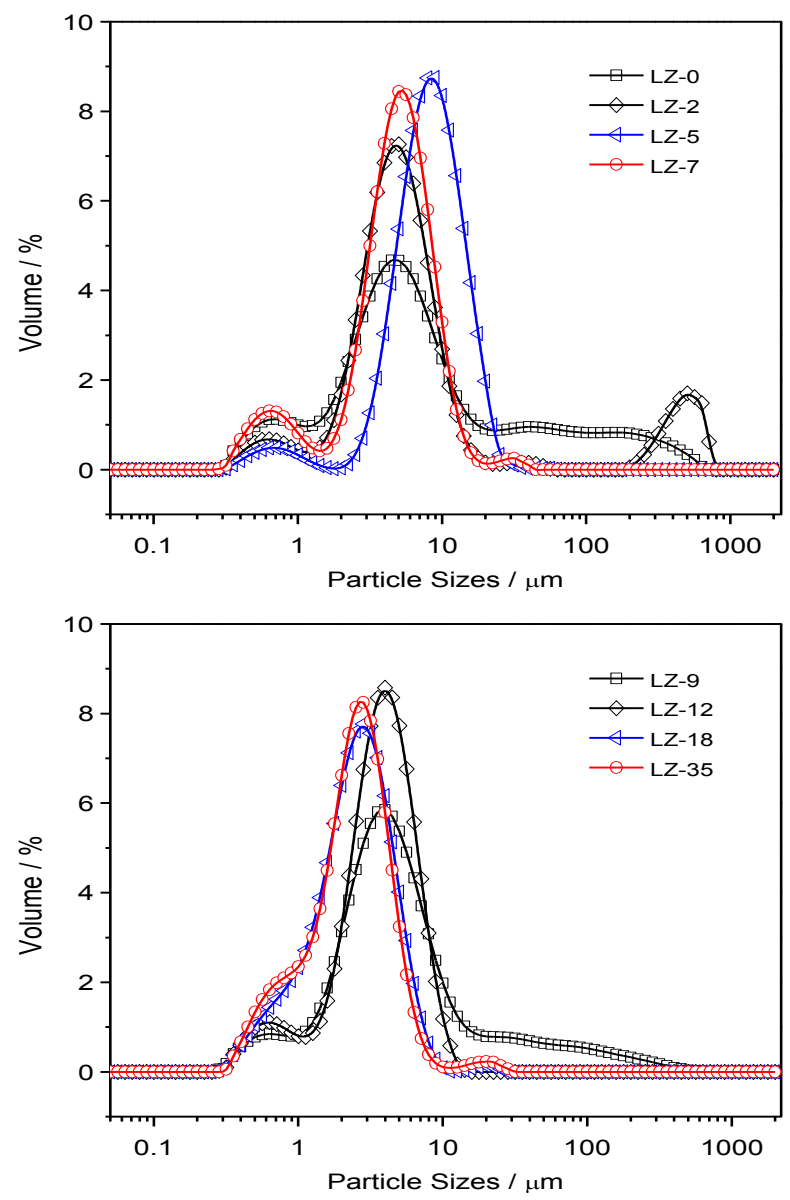

Figure 7. The particle size distributions of condensed combustion products (CCP) from combustion of LZ propellant grains under various pressures.

In terms of LZ propellants, the distributions are much different, which is highly dependent on the pressure. When the pressure is lower than $9 \mathrm{MPa}$, there are three major groups as the JZ propellant: micron and submicron $(<5 \mu \mathrm{m})$, media sizes $(5-15 \mu \mathrm{m})$, and large sizes $(>15 \mu \mathrm{m})$. However, we can see that there is a strange narrow peak and large shoulder peak at the size over $200 \mu \mathrm{m}$ at the pressure of ambient pressure and $2 \mathrm{MPa}$, which is probably due to presence of large agglomerated Nickel, which is too large to do the SEM analyses. It has been mentioned that the content of $\mathrm{Al}$ is largely dependent on the pressure and under lower pressure there is less interaction between $\mathrm{Al}$ and $\mathrm{Ni}$ in $\mathrm{LZ}$ propellant, resulting in lower burning efficiency and larger agglomeration.

When the pressure is over $18 \mathrm{MPa}$, the CCP from burning of LZ propellants, the amount of micron and submicron particles is greatly increased. Thus, the overall peak becomes narrower due to less agglomeration of the Nickel particles. For better quantitative comparison of the particle sizes, the detailed parameters are summarized in Table 3. It is clear that the specific surface area (SSA) of CCPs from the JZ propellant is less dependent on the pressure, which is in the range of 2.49 to $3.24 \mathrm{~m}^{2} \mathrm{~g}^{-1}$. It is 1.22 to 3.81 for the $\mathrm{LZ}$ propellant due to high pressure dependence of metallic nickel transformation and interaction of elemental $\mathrm{Ni}$ with $\mathrm{Al}_{2} \mathrm{O}_{3}$. The high pressure is favorable for more complete transformation and lower particle sizes [26]. The presence of less volatile products would decrease the size of $\mathrm{CCP}$ and, for instance, the formation of $\mathrm{AlF}_{3}$ would greatly mitigate the agglomeration of $\mathrm{Al}$ combustion by using organic fluorine-contained additives [27]. 
Table 3. Particle size distributions of the CCPs for involved JZ and LZ propellants.

\begin{tabular}{|c|c|c|c|c|c|c|c|c|c|c|c|}
\hline Samples & Obscuration & Residual & Concent. & Span & $D_{[4,3]}{ }^{a}$ & Uniformity & SSA & $\mathrm{D}_{[3,2]} \mathrm{b}$ & $d_{(0.1)}{ }^{c}$ & $d_{(0.5)}{ }^{d}$ & $\mathrm{~d}_{(0.9)}{ }^{e}$ \\
\hline $\mathrm{JZ}-7$ & 7.60 & 1.317 & 0.0027 & 3.154 & 4.981 & 1.050 & 3.06 & 1.959 & 0.794 & 3.179 & 10.819 \\
\hline JZ-12 & 8.90 & 1.144 & 0.0033 & 1.992 & 4.588 & 0.842 & 2.77 & 2.167 & 1.035 & 3.167 & 7.343 \\
\hline $\mathrm{JZ}-15$ & 8.55 & 1.798 & 0.0029 & 1.685 & 3.483 & 0.606 & 3.08 & 1.945 & 0.875 & 2.876 & 5.721 \\
\hline $\mathrm{JZ}-20$ & 9.31 & 1.125 & 0.003 & 2.512 & 3.959 & 0.905 & 3.24 & 1.855 & 0.834 & 2.661 & 7.519 \\
\hline $\mathrm{JZ}-25$ & 8.46 & 0.623 & 0.0037 & 3.967 & 9.567 & 1.780 & 2.49 & 2.41 & 0.99 & 4.116 & 17.317 \\
\hline LZ-0 & 8.37 & 0.571 & 0.0044 & 18.859 & 33.566 & 5.830 & 2.13 & 2.818 & 1.084 & 5.298 & 101.003 \\
\hline LZ-2 & 10.39 & 0.865 & 0.0057 & 61.074 & 54.834 & 10.800 & 1.83 & 3.286 & 1.995 & 4.788 & 294.406 \\
\hline LZ-5 & 8.23 & 1.614 & 0.0069 & 1.392 & 8.51 & 0.445 & 1.22 & 4.929 & 3.761 & 7.714 & 14.498 \\
\hline LZ-7 & 8.92 & 1.985 & 0.0042 & 1.708 & 5.126 & 0.530 & 2.35 & 2.549 & 0.986 & 4.561 & 8.777 \\
\hline LZ-9 & 10.16 & 0.482 & 0.0047 & 7.373 & 15.425 & 3.230 & 2.29 & 2.619 & 1.308 & 4.06 & 31.245 \\
\hline LZ-12 & 9.05 & 0.741 & 0.0035 & 1.541 & 3.758 & 0.464 & 2.64 & 2.27 & 1.18 & 3.481 & 6.544 \\
\hline LZ-18 & 9.28 & 1.561 & 0.0027 & 1.638 & 2.676 & 0.530 & 3.53 & 1.7 & 0.839 & 2.349 & 4.685 \\
\hline LZ-35 & 10.00 & 1.736 & 0.0028 & 1.562 & 2.496 & 0.533 & 3.81 & 1.574 & 0.75 & 2.191 & 4.171 \\
\hline
\end{tabular}

Notes: $a$, the weighted average of the particle size to the surface area; $b$, the weighted average of the particle size to the volume. c, particles whose diameter equals to or less than the value of $\mathrm{D}_{(0.1)}$, and the sum of the volume fractions of which accounts for ten percent; it is the same for d and e; SSA, specific surface area, in $\mathrm{m}^{2} / \mathrm{g}$.

In this case, the polymorphic transition of the metal oxide is also possible, e.g., $\alpha-\mathrm{Al}_{2} \mathrm{O}_{3}$ and $\theta-\mathrm{Al}_{2} \mathrm{O}_{3}$ may be transformed into $\delta-\mathrm{Al}_{2} \mathrm{O}_{3}$ and $\gamma-\mathrm{Al}_{2} \mathrm{O}_{3}$. In the presence of $\mathrm{Al}_{2} \mathrm{O}_{3}$ in $\mathrm{LZ}$ and $\mathrm{JZ}$ propellants as a stabilizer, it may react with carbon soot and many other organic residues to form various other condensed products instead of polymorphs of $\mathrm{Al}_{2} \mathrm{O}_{3}$. The cooling mode may also affect the particle size and phases content of the CCPs, but the comparative study under the same experimental conditions is fine [28].

\subsection{The Interface Structure of the Nanosized CCPs}

In order to observe the interface structures and the shape of the nano-sized CCPs, the TEM images of selected samples are collected and shown in Figures 5 and 6 for JZ and LZ propellants, respectively. The overall pictures of the nano-sized CCPs from combustion of JZ propellant under the pressure of 7, 12, and $15 \mathrm{MPa}$ are shown in Figure 8a-c. The maximum sizes of the CCPs increases with the pressure and then decreases with the shape changes. The particle shapes become less uniform when the pressure increases. Generally, the spherical particles with diameters in the range of $200-400 \mathrm{~nm}$ could be formed under the pressure of $7 \mathrm{MPa}$. There are some needles and nano-flakes can be observed when the pressure is over $12 \mathrm{MPa}$, indicating new crystal phases. Large irregular aggregates could be found when the pressure achieves $25 \mathrm{MPa}$, where the spherical particle has a diameter of about 200-300 nm.

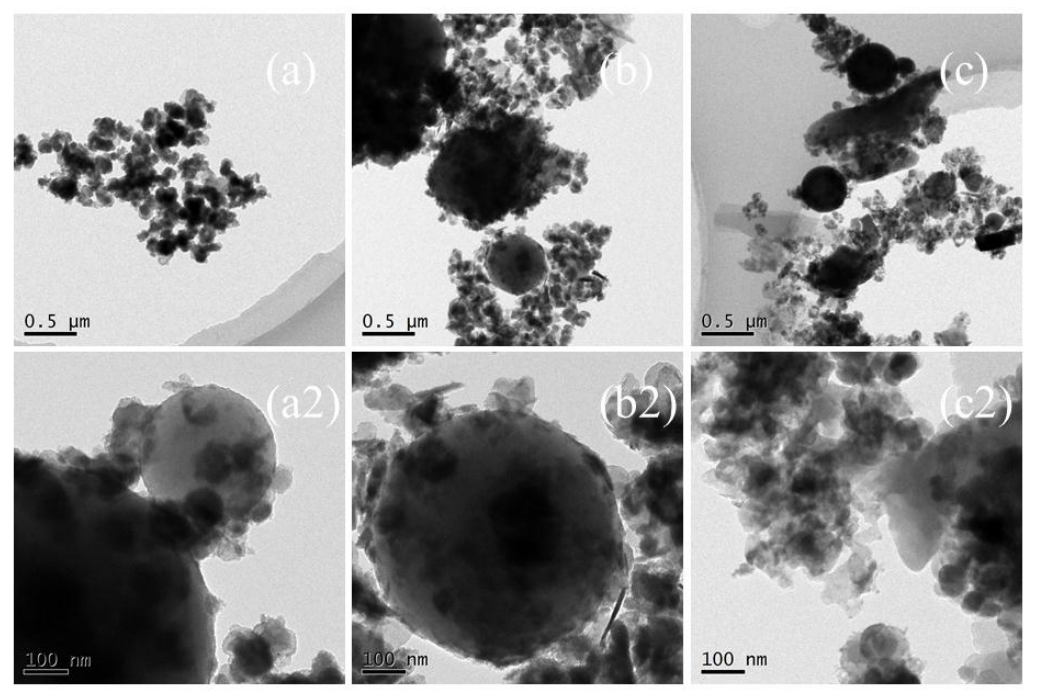

Figure 8. The TEM images of nano-sized CCPs of JZ propellant grains $\left(\mathbf{a}, \mathbf{a}_{2}\right) \mathrm{JZ}-7 ;\left(\mathbf{b}, \mathbf{b}_{\mathbf{2}}\right) \mathrm{JZ}-12$; $\left(\mathrm{c}, \mathrm{c}_{2}\right) \mathrm{JZ}-25$. 
In comparison, as shown in Figure $9 \mathrm{a}-\mathrm{c}$, the maximum sizes of the nano-sized CCPs increases with the pressure and the morphology changes as well. There are generally three types of particle shapes: stacked layers, spherical, and long needle-like. Under the ambient pressure, there are a large amount of small particles with diameter of less than $100 \mathrm{~nm}$, which are deposited on stack-layered structures. When the pressure increases to $7 \mathrm{MPa}$, the layers become thicker and the needles appears with length over $500 \mathrm{~nm}$ and diameter less than $50 \mathrm{~nm}$. With the pressure further increases, the length and diameter of the needle structure decreases (Figure 9c1). Generally, for LZ propellant, the spherical particles with diameters in the range of 50-100 nm under lower pressure, but it could be over $500 \mathrm{~nm}$ under the pressure of $35 \mathrm{MPa}$. Large irregular aggregates could be stick to the spherical particles at this high pressure. It has been proposed for metallized propellants that the irregular agglomerates usually larger than spherical agglomerates [29,30]. The formation of irregular agglomerates was proposed to occur by three steps: deformation of spherical metal drops, combination of particles with various shapes, and formation of irregular aggregations.

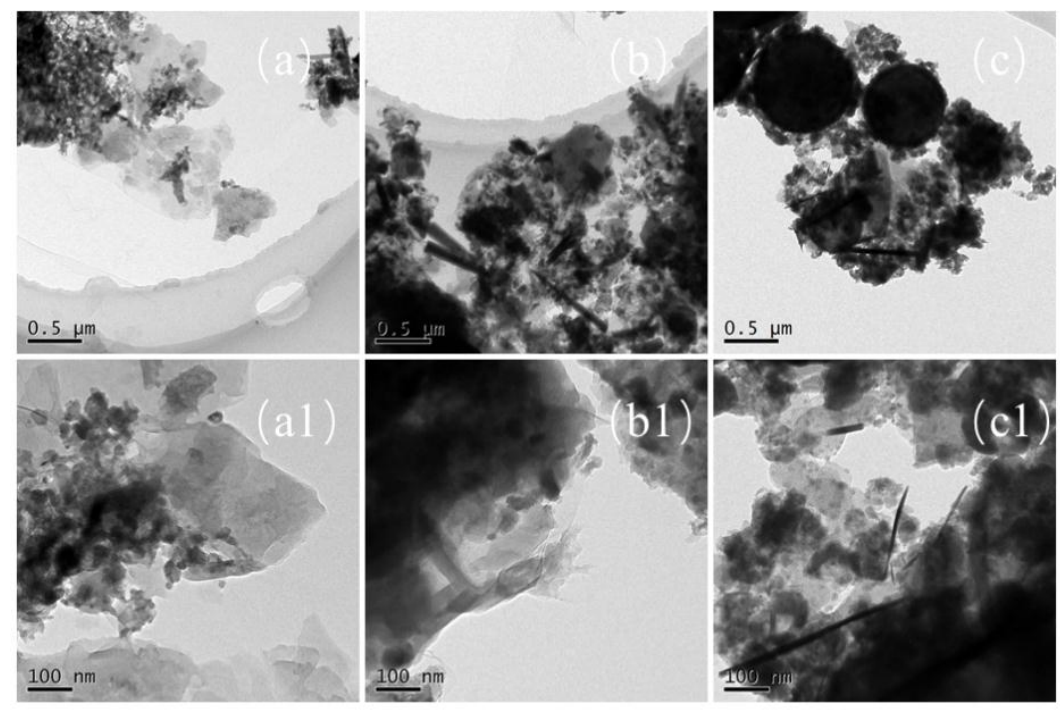

Figure 9. The TEM images of nano-sized CCPs of LZ propellant grains $\left(\mathbf{a}_{,}, \mathbf{a}_{\mathbf{1}}\right)$ LZ-0; $\left(\mathbf{b}, \mathbf{b}_{\mathbf{1}}\right)$ LZ-7; $\left(\mathbf{c}, \mathbf{c}_{\mathbf{1}}\right)$ LZ-35.

\subsection{The Chemical Compositions of the CCPS}

As the most important step, the determination of the crystal phases inside the CCPs has to be done, to show the inherent reaction mechanism in the gas phase under a real rocket motor flow condition. The powder X-ray (PXRD) spectra have been collected, with the crystal phases identified in Figures 10 and 11. The quantitative analyses of the content of the selected major phases are listed in Tables S4 and S5.

It has been shown from Figures 10 and 11 that the compositions of the crystal phases of CCPs are highly dependent on the pressure. In general, the CCPs from the LZ propellant are much more diverse than those from the JZ propellant. In the case of the JZ propellant under the attempted pressures, only three to four major phases have been identified under each pressure. The metallic copper is shown when the pressure is not higher than $20 \mathrm{MPa}$, the content slight decreases with the increase of pressure. It means the organic copper salts would transform to $\mathrm{CuO}$ first, which further participate in the reaction with carbon soot as an oxidizer. The presences of $\mathrm{AlCu}_{3}$ at the pressure of 12 and $35 \mathrm{MPa}$ and $\mathrm{AlCu}_{4}$ at the pressure of $15 \mathrm{MPa}$ indicate interaction of the resulted metallic $\mathrm{Cu}$ with the $\mathrm{Al}_{2} \mathrm{O}_{3}$. Only $13 \%$ of $\mathrm{Al}_{2} \mathrm{O}_{3}$ is found in $\mathrm{CCP}$ of $\mathrm{JZ}$ under pressure of $20 \mathrm{MPa}$, which means the reaction between $\mathrm{Al}_{2} \mathrm{O}_{3}$ with the other products in the gas phase is not complete at this pressure. It may be transformed to $\mathrm{Al}_{2} \mathrm{O}$ at lower pressure (e.g., $<7 \mathrm{MPa}$ ). 

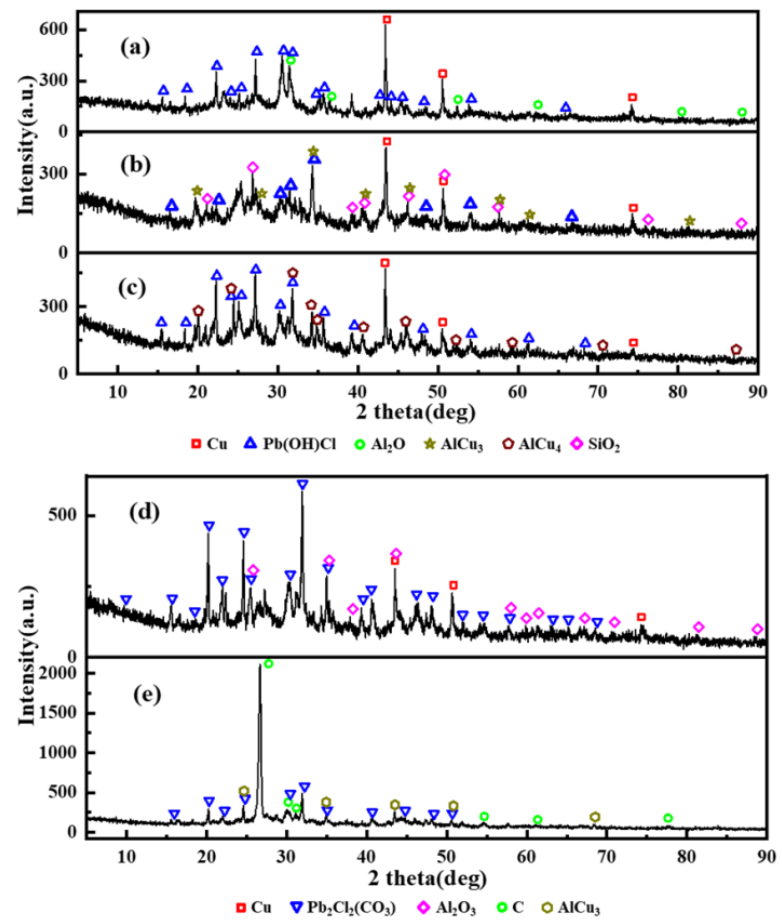

Figure 10. X-ray diffraction (XRD) results of JZ propellant grains combustion product; (a-e) represent pressure of $7,12,15,20$, and $25 \mathrm{MPa}$ ).

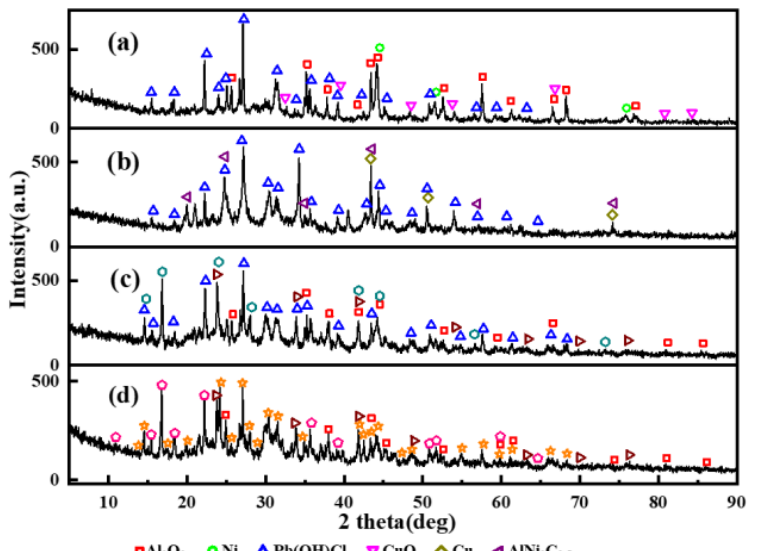

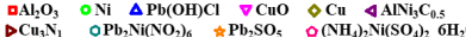

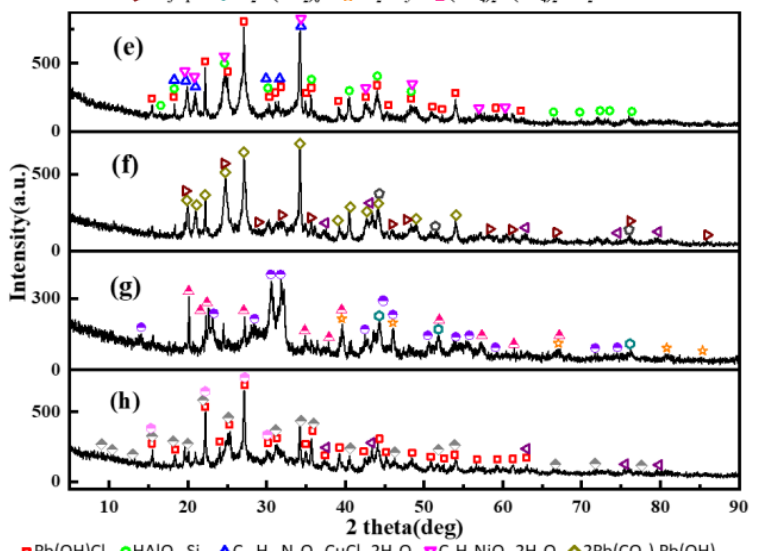

$\square \mathrm{Pb}(\mathrm{OH}) \mathrm{Cl}$ OHAlO $\mathrm{Si}_{4} \Delta \mathrm{C}_{12} \mathrm{H}_{27} \mathrm{~N}_{3} \mathrm{O}_{6} \mathrm{CuCl}_{2} \mathrm{H}_{2} \mathrm{O} \nabla \mathrm{C}_{2} \mathrm{H}_{2} \mathrm{NiO}_{4} 2 \mathrm{H}_{2} \mathrm{O} \diamond 2 \mathrm{~Pb}\left(\mathrm{CO}_{3}\right) \mathrm{Pb}(\mathrm{OH})_{2}$ oC $4 \mathrm{NiO} \triangleright \mathrm{AlCu}_{4}$ ONi $\Rightarrow A I N \quad \theta \mathrm{b}_{4} \mathrm{O}_{3} \mathrm{Cl}_{2} \mathrm{H}_{2} \mathrm{O} \Delta \mathrm{Cu}_{1.8} \mathrm{~S} \rightarrow \mathrm{CH}_{18} \mathrm{AlN}_{3} \mathrm{O}_{14} \mathrm{~S}_{2} \rightarrow \mathrm{Cu}\left(\mathrm{NO}_{3}\right)_{2} 3 \mathrm{H}_{2} \mathrm{O}$

Figure 11. XRD results for condensed combustion products of LZ propellants; $(\mathbf{a}-\mathbf{h})$ represent pressure of $0,2,5,7,9,12,18$, and $35 \mathrm{MPa}$. 
The lead salt as the catalyst has been transformed in to $\mathrm{Pb}(\mathrm{OH}) \mathrm{Cl}$ at the pressure lower than $15 \mathrm{MPa}$ or $\mathrm{Pb}_{2} \mathrm{Cl}_{2}\left(\mathrm{CO}_{3}\right)$ when the pressure is higher than $20 \mathrm{MPa}$. The $\mathrm{Pb}_{2} \mathrm{Cl}_{2}\left(\mathrm{CO}_{3}\right)$ is also so-called phosgenite as a naturally formed mineral, which are usually colorless and transparent. This mineral is rather sectile and consequently was earlier known as corneous lead. This finding may help in designing novel preparation method for this mineral by a flame synthesis process using lead-containing propellant as a precursor. Besides, a large amount of carbon soot was formed when the pressure achieves $35 \mathrm{MPa}$, due to extinguish of the CCP intermediates caused by fast pressure drop after the peak pressure (see in Figure 2). The unique product $\mathrm{SiO}_{2}$ from JZ-12 is due to the contaminant of the exhausted insulating materials after oxidation.

In comparison, as shown in Figure 11 and Table S5, it is similar to LZ propellants, only three or four major crystalline components have been found under each pressure. $\mathrm{The} \mathrm{Pb}(\mathrm{OH}) \mathrm{Cl}$ is the most common product of lead salts as the catalysts, whereas the copper salt could be transformed into various compounds depending on the pressure, e.g., it is $\mathrm{CuO}$ under ambient pressure. It is logical, then, that the gas phase reaction was not realized under the ambient pressure and the $\mathrm{CuO}$ as the condensed decomposition product of organic cooper salt did not change. The $\mathrm{Cu}_{3} \mathrm{~N}_{1}, \mathrm{C}_{12} \mathrm{H}_{27} \mathrm{~N}_{3} \mathrm{O}_{6} \cdot \mathrm{CuC}_{12} \cdot 2 \mathrm{H}_{2} \mathrm{O}$, $\mathrm{Cu}_{1.8} \mathrm{~S}$ and $\mathrm{Cu}\left(\mathrm{NO}_{3}\right)_{2} \cdot 3 \mathrm{H}_{2} \mathrm{O}$ are unique copper based compounds under the pressure of $7,9,18$, and $35 \mathrm{MPa}$. The lead salt would transform to $\mathrm{Pb}_{2} \mathrm{SO}_{5}, 2 \mathrm{~Pb}\left(\mathrm{CO}_{3}\right) \cdot \mathrm{Pb}(\mathrm{OH})_{2}$ and $\mathrm{Pb}_{4} \mathrm{O}_{3} \mathrm{Cl}_{2} \cdot \mathrm{H}_{2} \mathrm{O}$ at the pressure of 7, 12, and $18 \mathrm{MPa}$. At the pressure of $5 \mathrm{MPa}$, the elemental lead even combines with nickel to form $\mathrm{Pb}_{2} \mathrm{Ni}\left(\mathrm{NO}_{2}\right)_{6}$. It is interesting that at the same pressure of $12-15 \mathrm{MPa}$, no matter the $\mathrm{LZ}$ or JZ propellant, the copper aluminum alloy could be formed. It is $\mathrm{AlCu}_{4}$ for the $\mathrm{LZ}$ propellant and $\mathrm{AlCu}_{3}$ or $\mathrm{AlCu}_{4}$ for the $\mathrm{JZ}$ propellant.

As mentioned earlier in this paper, the presence of metallic nickel in the formulation makes the compositions of CCPs largely dependent on the pressure. The diverse of the crystalline components of CCPs derives mostly from the nickel element. Under ambient pressure, the metallic nickel is presented due to incomplete combustion, and the other nickel-based compounds are not shown. With the increase of pressure ( $>5 \mathrm{MPa}$ ), the nickel-based CCPs are $\mathrm{Pb}_{2} \mathrm{Ni}\left(\mathrm{NO}_{2}\right)_{6},\left(\mathrm{NH}_{4}\right)_{2} \mathrm{Ni}\left(\mathrm{SO}_{4}\right)_{2} \cdot 6 \mathrm{H}_{2} \mathrm{O}$, $\mathrm{C}_{2} \mathrm{H}_{2} \mathrm{NiO}_{4} \cdot 2 \mathrm{H}_{2} \mathrm{O}$, and $\mathrm{NiO}$. At the pressure of $9 \mathrm{MPa}$, the CCP contains Si-based compound $\mathrm{HAlO}_{10} \mathrm{Si}_{4}$, which is different from the $\mathrm{JZ}$ propellant $\left(\mathrm{SiO}_{2}\right)$. One could notice above that the high dependence of gas phase reactions on pressure, which results in a variety of CCPs in terms of different compositions and morphologies. In terms of Boron-based metal fuels, such as B-Mg and B-Al, the CCPs with ferrocene as the catalyst could be even more complicated. It has been shown that the condensed-phase products are mainly composed of $\mathrm{B}, \mathrm{C}, \mathrm{B}_{4} \mathrm{C}$ (or $\mathrm{B}_{12} \mathrm{C}_{2}$ ), $\mathrm{BN}, \mathrm{Mg}, \mathrm{MgO}, \mathrm{MgAl}_{2} \mathrm{O}_{4}, \mathrm{Al} \mathrm{Al}_{2} \mathrm{O}_{3}, \mathrm{AlCl}_{3}$, $\mathrm{NH}_{4}\left[\mathrm{Mg}\left(\mathrm{H}_{2} \mathrm{O}\right)_{6}\right] \mathrm{Cl}_{3}, \mathrm{NH}_{4} \mathrm{Cl}$, and $\mathrm{Fe}_{3} \mathrm{O}_{4}$ [24]. It was shown that the high pressure is not so benefit to high efficiency secondary combustion of boron in gas phase due to formation of less active boron carbide, graphite, and h-BN. As a comparison, the CCPs from aluminum boride and boron-aluminum blends are very similar, with the common ingredients of $\mathrm{B}, \mathrm{Al}, \mathrm{B}_{2} \mathrm{O}_{3}, \mathrm{Al}_{2} \mathrm{O}_{3}, \mathrm{AlN}$, and $\mathrm{Al}_{5} \mathrm{O}_{6} \mathrm{~N}$, showing incomplete combustion due to low pressure [31]. In our case, the high pressure is favorable for secondary reaction of $\mathrm{Ni}$-based compounds and the $\mathrm{NiO}$ is the major product under higher pressure, without metallic nickel detected.

\section{Conclusions}

In this paper, the dependences of the morphology, particle sizes, and compositions of the CCPs of modified double-base propellants on the chamber pressure and nickel inclusion have been evaluated under conditions for a real rocket motor operation. The following conclusions could be made:

(1) The peak chamber pressure has been successfully modulated by changing the size of the throat of the motor. The maximum pressure achieved herein is about $35 \mathrm{MPa}$, and the lowest one is the ambient pressure.

(2) With the pressure increase, the average particle size of the CCPs decreases. In presence of metallic $\mathrm{Ni}$, the CCPs have a variety of morphologies depending on the pressure. The most typical ones are spherical particles, large layered structures, and small flakes coated on large particles. The SSA 
of CCPs from the JZ propellant is less dependent on the pressure, which is in the range of 2.49 to $3.24 \mathrm{~m}^{2} \mathrm{~g}^{-1}$, whereas it is 1.22 to 3.81 for the LZ propellant due to high pressure dependence of metallic nickel transformation and interaction of elemental $\mathrm{Ni}$ with $\mathrm{Al}_{2} \mathrm{O}_{3}$.

(3) The $\mathrm{C}, \mathrm{N}, \mathrm{O}, \mathrm{Al}, \mathrm{Cu}, \mathrm{Pb}$, and $\mathrm{Si}$ are the major elements presented on the surfaces the $\mathrm{CCP}$ particles. The micron-sized CCPs from combustion of both propellants can be divided into three groups in terms of particle sizes, but the LZ propellant containing metallic nickel has larger CCPs sizes.

(4) The compositions of CCPs from LZ propellant are much more diverse than those from JZ propellant, but only three to four major phases have been found under each pressure. The metallic copper is presented in CCPs for both propellants when the chamber pressure is low.

(5) The lead salt as the catalyst has been transformed in to $\mathrm{Pb}(\mathrm{OH}) \mathrm{Cl}$ as the most common products of lead-based catalysts at the pressure lower than $15 \mathrm{MPa}$ or $\mathrm{Pb}_{2} \mathrm{Cl}_{2}\left(\mathrm{CO}_{3}\right)$ when the pressure is higher than $20 \mathrm{MPa}$. The copper salt and nickel could be transformed into various compounds depending on the pressure and when pressure is greater than $5 \mathrm{MPa}$, the nickel-based CCPs contain one of the following phases: $\mathrm{Pb}_{2} \mathrm{Ni}\left(\mathrm{NO}_{2}\right)_{6},\left(\mathrm{NH}_{4}\right)_{2} \mathrm{Ni}\left(\mathrm{SO}_{4}\right)_{2} \cdot 6 \mathrm{H}_{2} \mathrm{O}, \mathrm{C}_{2} \mathrm{H}_{2} \mathrm{NiO}_{4} \cdot 2 \mathrm{H}_{2} \mathrm{O}$, and $\mathrm{NiO}$.

Supplementary Materials: The following are available online at http:/ /www.mdpi.com/2079-4991/9/3/381/s1, Figure S1: The EDS spectra of CCPs from JZ propellant grains, Figure S2: The EDS spectra of CCPs from LZ propellant grains; Figure S3: The particle size distribution curves for JZ propellant grains combustion under various pressures with repeated tests; Figure S4: The particle size distribution curves for LZ propellant grains combustion under various pressures with repeated tests; Table S1: Element distribution results of JZ and LZ propellant grains combustion products; Table S2: A summary of the CCPs particle distributions for JZ propellant grains. Table S3: Particle distribution of LZ propellant grains combustion products; Table S4: Chemical compositions of the CCPs of JZ propellants at various pressures; Table S5: Chemical compositions of the CCPs of LZ propellants at various pressures.

Author Contributions: Conceptualization, Q.-L.Y. and J.-Q.L.; methodology, L.L. and S.H.; formal analysis, D.T.; investigation, Q.-L.Y. and X.F.; resources, J.-Q.L.; data curation, Y.W.; writing - original draft preparation, Q.-L.Y.; writing-review and editing, Q.-L.Y.; project administration, J.-Q.L. and Q.-L.Y.; funding acquisition, J.-Q.L.

Funding: This research was funded by "National Natural Science Foundation of China, grant number 51776176" and "Fundamental Research Funds from Chinese H863 plan grant number 2018KC020167".

Acknowledgments: The basic research funding from Scientific Research Ordering Bureau of EDDM China with project number 61407200204 is also appreciated. Xiaojiang Li and Wuxi Xie prepared the propellant charges in MCRI. The graduate students Huan Liu, Jieyao Lyu and Peng Yang, who help a lot in the experiments of condensed products collections, are also greatly appreciated.

Conflicts of Interest: The authors declare no conflict of interest. The funders had no role in the design of the study; in the collection, analyses, or interpretation of data; in the writing of the manuscript, or in the decision to publish the results.

\section{References}

1. Yan, Q.-L.; Zhao, F.-Q.; Kuo, K.K.; Zhang, X.-H.; Zeman, S.; DeLuca, L.T. Catalytic Effects of Nano Additives on Decomposition and Combustion of RDX-, HMX-, and AP-Based Energetic Compositions. Prog. Energy Combust. Sci. 2016, 57, 75-136. [CrossRef]

2. Yan, Q.-L.; Li, X.-J.; Wang, Y.; Zhang, W.-H.; Zhao, F.-Q. Combustion mechanism of double-base propellant containing nitrogen heterocyclic nitramines (I): The effect of heat and mass transfer to the burning characteristics. Combust. Flame 2009, 156, 633-641. [CrossRef]

3. Dong, X.-F.; Yan, Q.-L.; Zhang, X.-H.; Cao, D.-L.; Xuan, C.-L. Effect of potassium chlorate on thermal decomposition of cyclotrimethylenetrinitramine (RDX). J. Anal. Appl. Pyrol. 2012, 93, 160-164. [CrossRef]

4. Yan, Q.-L.; Song, Z.-W.; Shi, X.-B.; Yang, Z.-Y.; Zhang, X.-H. Combustion mechanism of double-base propellant containing nitrogen heterocyclic nitramines (II): The temperature distribution of the flame and its chemical structure. Acta Astronaut. 2009, 64, 602-614. [CrossRef]

5. Wu, X.-G.; Yan, Q.-L.; Guo, X.; Qi, X.-F.; Li, X.-J.; Wang, K.-Q. Combustion efficiency and pyrochemical properties of micron-sized metal particles as the components of modified double-base propellant. Acta Astronaut. 2011, 68, 1098-1112. [CrossRef] 
6. Wang, Y.-L.; Yan, Q.-L.; An, T.; Chen, B.; Ji, Y.-P.; Wang, L.; Zhao, F.-Q. Unraveling the Effect of Anthraquinone Metal Salts as Wide-range Plateau Catalysts to Enhance the Combustion Properties of Solid Propellants. Cent. Eur. J. Energy Mater. 2018, 15, 376-390. [CrossRef]

7. Jackson, T.L. Modeling of heterogeneous propellant combustion: A survey. AIAA J. 2012, 50, 993-1006. [CrossRef]

8. Babuk, V.A.; Nizyaev, A.A. Modeling of evolution of the coarse fraction of condensed combustion products on a surface of burning aluminized propellant and within a combustion products flow. Int. J. Energy Mater. Chem. Propuls. 2017, 16, 23-38. [CrossRef]

9. Babuk, V.A.; Budnyi, N.L.; Ivonenko, A.N.; Nizyaev, A.A. Simulation of Characteristics of Condensed Products in a Combustion Chamber. Combust. Explos. Shock Waves 2018, 54, 301-308. [CrossRef]

10. Ye, Z.-W.; Yu, Y.-G. Numerical Simulation of Quenched Combustion Model for AP/HTPB Propellant under Transient Depressurization. Propell. Explos. Pyrot. 2017, 42, 1085-1094. [CrossRef]

11. Gaduparthi, T.; Pandey, M.; Chakravarthy, S.R. Gas phase flame structure of solid propellant sandwiches with different reaction mechanisms. Combust. Flame 2016, 164, 10-21. [CrossRef]

12. Jensen, T.L.; Moxnes, J.F.; Unneberg, E.; Dullum, O. Calculation of decomposition products from components of gunpowder by using ReaxFF reactive force field molecular dynamics and thermodynamic calculations of equilibrium composition. Propell. Explos. Pyrot. 2014, 39, 830-837. [CrossRef]

13. Anderson, W.R.; Meagher, N.E.; Vanderhoff, J.A. Dark zones of solid propellant flames: Critically assessed datasets, quantitative model comparison, and detailed chemical analysis. Combust. Flame 2011, 158, 1228-1244. [CrossRef]

14. Yang, Y.; Zhao, F.; Xu, H.; Pei, Q.; Jiang, H.; Yi, J.; Xuan, C.; Chen, S. Hydrogen-enhanced combustion of a composite propellant with $\mathrm{ZrH}_{2}$ as the fuel. Combust. Flame 2018, 18, 67-76. [CrossRef]

15. Pang, W.; De Luca, L.T.; Fan, X.; Maggi, F.; Xu, H.; Xie, W.; Shi, X. Effects of Different Nano-Sized Metal Oxide Catalysts on the Properties of Composite Solid Propellants. Combust. Sci. Technol. 2016, 188, 315-328. [CrossRef]

16. Ishitha, K.; Ramakrishna, P.A. Studies on the role of iron oxide and copper chromite in solid propellant combustion. Combust. Flame 2014, 161, 2717-2728. [CrossRef]

17. Sinditskii, V.P.; Chernyi, A.N.; Marchenkov, D.A. Mechanisms of combustion catalysis by ferrocene derivatives. 1. Combustion of ammonium perchlorate and ferrocene. Combust. Explos. Shock Waves 2014, 50, 51-59. [CrossRef]

18. Bai, Y.-J.; Xu, T.-W.; Li, Y. Parameters of combustor condensed phase particles form analysis for overload simulation test. J. Solid Rocket Technol. 2017, 40, 409-413, 419.

19. Wu, Q.; Chen, L.-Q.; Wang, Y.-X.; Yang, Y.-X. Test method of combustion efficiency for condensed products of boron-based propellant in secondary combustion chamber of solid ducted rocket. J. Solid Rocket Technol. 2014, 37, 134-138.

20. DeLuca, L.T.; Galfetti, L.; Colombo, G.; Maggi, F.; Bandera, A.; Babuk, V.A.; Sinditskii, V.P. Microstructure effects in aluminized solid rocket propellants. J. Propuls. Power 2010, 26, 724-733. [CrossRef]

21. Soo, M.; Goroshin, S.; Bergthorson, J.M.; Frost, D.L. Reaction of a particle suspension in a rapidly-heated oxidizing gas. Propell. Explos. Pyrot. 2015, 40, 604-612. [CrossRef]

22. Kalman, J.; Demko, A.R.; Varghese, B.; Matusik, K.E.; Kastengren, A.L. Synchrotron-based measurement of aluminum agglomerates at motor conditions. Combust. Flame 2018, 196, 144-146. [CrossRef]

23. Patidar, L.; Thynell, S.T. Quantum mechanics investigation of initial reaction pathways and early ring-opening reactions in thermal decomposition of liquid-phase RDX. Combust. Flame 2017, 178, 7-20. [CrossRef]

24. Liu, L.-L.; He, G.-Q.; Wang, Y.-H.; Hu, S.-Q. Chemical analysis of primary combustion products of boron-based fuel-rich propellants. RSC Adv. 2015, 5, 101416-101426. [CrossRef]

25. Miller, W.H.; Barrington, D.K. A Review of Contemporary Solid Rocket Motor Performance Prediction Techniques. J. Spacecr. Rockets 1970, 7, 225-237.

26. Arkhipov, V.A.; Zarko, V.E.; Zharova, I.K.; Zhukov, A.S.; Kozlov, E.A.; Aksenenko, D.D.; Kurbatov, A.V. Solid propellant combustion in a high-velocity cross-flow of gases. Combust. Explos. Shock Waves 2016, 52, 497-513. [CrossRef]

27. Wang, W.-L.; Li, J.-M.; Yang, R.-J.; Liu, Z.; Li, S.-P. Influence of Organic Fluorine-contained Additives on Condensed Combustion Products of Aluminized Polyether Propellants. Acta Armament. 2017, 38, 704-710. 
28. Hu, X.; Pang, A.-M.; Wang, Y.; Tang, Q.; Han, L.-P. Effects of collection methods on characteristics of condensed combustion products of NEPE propellant. J. Solid Rocket Technol. 2017, 40, 65-69.

29. Ao, W.; Liu, P.; Yang, W. Agglomerates, smoke oxide particles, and carbon inclusions in condensed combustion products of an aluminized GAP-based propellant. Acta Astronaut. 2016, 129, 147-153. [CrossRef]

30. Popenko, E.M.; Gromov, A.A.; Pautova, Y.I.; Chaplina, E.A.; Ritzhaupt-Kleissl, H.-J. SEM-EDX study of the crystal structure of the condensed combustion products of the aluminum nanopowder burned in air under the different pressures. Appl. Surf. Sci. 2011, 257, 3641-3644. [CrossRef]

31. Liang, D.; Xiao, R.; Liu, J.; Wang, Y. Ignition and heterogeneous combustion of aluminum boride and boron-aluminum blend. Aerosp. Sci. Technol. 2019, 84, 1081-1091. [CrossRef]

(C) 2019 by the authors. Licensee MDPI, Basel, Switzerland. This article is an open access article distributed under the terms and conditions of the Creative Commons Attribution (CC BY) license (http://creativecommons.org/licenses/by/4.0/). 